\title{
MODELLING OF TEMPERATURES IN REFRIGERATED TRUCK BODY SUPPLIED FROM HEAT RESERVOIR
}

\author{
S. Kwaśniowski ${ }^{*}$, Sz. Haładyn ${ }^{* *}$
}

\begin{abstract}
The paper presents a calculation model of heat exchange in the body of a refrigerated truck supplied from a cold reservoir. On the basis of this model, the temperature inside the body was simulated, taking into account: changes in ambient temperature during a hot day, changes in solar irradiance, loss of load, distributed during the running of the vehicle. In the era of energy savings, this solution - compared to traditional solutions in this area - allows for rational management of the energy needed to supply the car body. The MATLAB Simulink software package was used for modeling.
\end{abstract}

Keywords: Isothermal car bodies, heat transfer dynamics, modelling, circulating cooling.

\section{Introduction}

For the transport of perishable goods, isothermal cars are used - without a source of cold, refrigerated vehicles with a non-mechanical source of cold, refrigerated vehicles with refrigerating (compressorbased) units, and multi-temperature bodies supplied, depending on the need, either from a refrigerating unit or from a heating device.

The technical requirements for these vehicles are regulated by the international agreement ATP (1970) and Bienczak, Zwierzycki, (2006). The case discussed in the paper concerns a refrigerated truck body cooled by circulation from a cold reservoir located outside the cargo space. The advantage of this solution is the possibility to switch off the cooling when there is no need to cool the cargo space. Such a possibility is not provided by the supply system of a typical refrigerated body. A schematic diagram of a typical refrigerated body is shown in Figure 1.

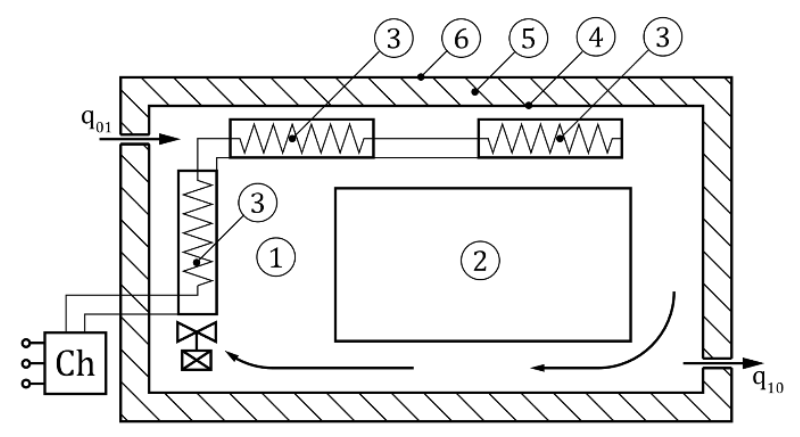

Fig. 1: Schematic diagram of a refrigerated truck body cooled by means of eutectic plates. 1 - internal air, 2 - cargo, 3 - eutectic plates, 4 - internal body sheathing, 5 - thermal insulation of the body, 6 - external body sheathing, Ch - external refrigerating unit for freezing eutectic plates.

Dr. Eng. Stanislaw Kwasniowski: Faculty of Mechanical Engineering, Wrocław University of Science and Technology; 27 Wybrzeze Wyspianskiego st.; 50-370, Wroclaw; PL, stanislaw.kwasniowski@pwr.edu.pl, ORCID:0000-0001-9997-1429

** Eng. Szymon Haladyn: Faculty of Mechanical Engineering, Wrocław University of Science and Technology; 27 Wybrzeze Wyspianskiego st.; 50-370, Wroclaw; PL, 222908@student.pwr.edu.pl 
Refrigerated trucks are cooled by means of plates filled with eutectic solution whose phase transition temperature is low, e.g. $-32^{\circ} \mathrm{C}$ They are located on the ceiling of the body and on the front wall. These plates have flat shapes of dimensions: $70 \times 700 \times 1590 \mathrm{~mm}$ (Guidance materials CARRIER and SÜTRACK company) or constitute several dozen oblong reservoirs of dimensions $60 \times 120 \times$ $1000 \mathrm{~mm}$, forming a type of grate. Inside the reservoirs there is refrigerant and refrigeration system lines, which the system is periodically used to freeze the plates during a 24-hour vehicle standstill. The amount of cold stored in the plates is to ensure the proper temperature of the interior of the vehicle for a period of ten-odd hours of operation; then the distribution of frozen goods to collection points takes place. To freeze the plates, compressor-based refrigerating units with electric compressor drive are employed. The freezing process usually takes place at night. The disadvantage of this system is that it is not possible to stop the interior cooling process when there is no cargo inside. In such case, energy is unnecessarily wasted Kwasniowski (1997) and Kwasniowski, Grajnert (1998).

This disadvantage is non-existent in the case of circulation cooling with the use of a cold reservoir (fig. 2).

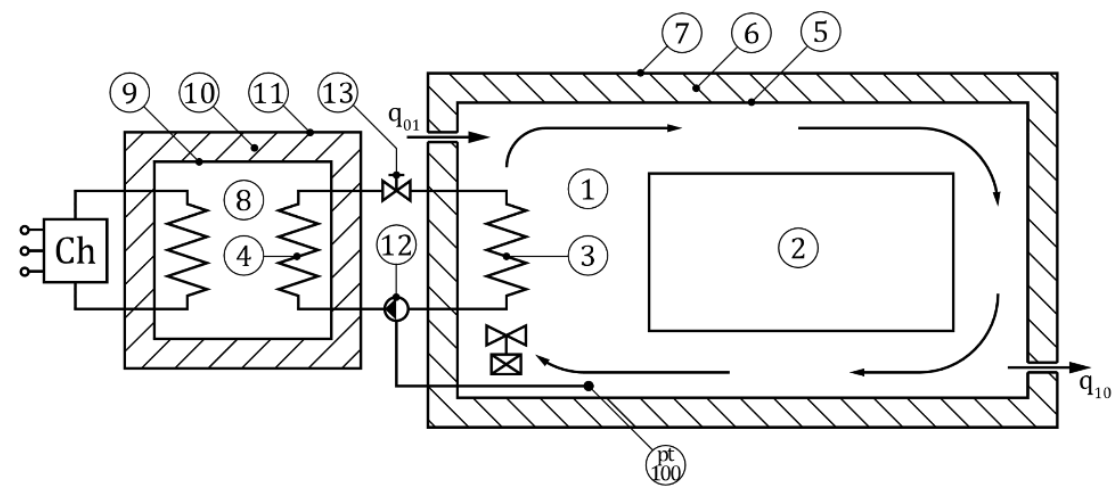

Fig. 2: Schematic diagram of a refrigerated truck body cooled by circulation from a cold reservoir 1 indoor air, 2 - cargo, 3 - body interior cooling coil, 4 - cooling coil in cooling reservoir, 5 - body interior sheathing, 6 - body thermal insulation, 7 - body exterior sheathing, 8 - cooling reservoir,

9 - reservoir interior sheathing, 10 - reservoir thermal insulation, 11 - reservoir exterior sheathing, 12 - pump, 13 - refrigerant shut-off valve, Ch - refrigerating unit, pt100 thermocouple

The difference in operation consists in the use of an additional cold reservoir with a thermal capacity equal to the sum of the capacity of the eutectic plates or grate. The reservoir is situated outside the cargo space of the body, and has adequate thermal insulation. During standstills of the vehicle, the reservoir is cooled by the Ch refrigerating unit. Heat recovery from the body by the refrigerant can be deactivated by the shut-off valve 13 Zajac, Kwasniowski (2015).

\section{Simulation model of circulating-cooled refrigerating truck body}

The difference in operation consists in the use of an additional cold reservoir with a thermal capacity equal to the sum of the capacity of the eutectic plates or grate. The reservoir is situated outside the cargo space of the body, and has adequate thermal insulation. During standstills of the vehicle, the reservoir is cooled by the Ch refrigerating unit. Heat recovery from the body by the refrigerant can be deactivated by shut-off valve 13 and is controlled by pt100 temperature sensor Zajac, P. (2017).

$$
\begin{gathered}
q_{1}=-q_{3,1}+q_{0,1}-q_{1,0}+q_{2,1}+q_{5,1}+q_{p t, 1} \\
q_{2}=-q_{2,1} \\
q_{3}=+q_{3,1}+q_{4,3} \\
q_{4}=-q_{4,8}-q_{4,3} \\
q_{5}=q_{6,5}-q_{5,1} \\
q_{6}=q_{7,6}-q_{6,5} \\
q_{7}=q_{0,7}-q_{7,6}+q_{p} \\
q_{8}=q_{9,8}+q_{4,8}-q_{a} \\
q_{9}=-q_{9,8}+q_{9,10}
\end{gathered}
$$




$$
\begin{gathered}
q_{10}=q_{11,10}-q_{10,9} \\
q_{11}=q_{0,11}-q_{11,10} \\
q_{p t}=-q_{p t, 1}
\end{gathered}
$$

Under Newton's assumption of the proportionality of heat flux to temperature difference, the system of equations can be transformed into a system of differential equations describing the dynamics of heat exchange in the refrigerated body with a controlled cold reservoir:

$$
\begin{gathered}
c_{1} \dot{T}_{1}=-c_{3,1}\left(T_{3}-T_{1}\right)+c_{0,1}\left(T_{0}\right)-c_{1,0}\left(T_{1}\right)+c_{2,1}\left(T_{2}-T_{1}\right)+c_{5,1}\left(T_{5}-T_{1}\right)+c_{p t, 1}\left(T_{p t}-T_{1}\right)(13) \\
c_{2} \dot{T}_{2}=-c_{2,1}\left(T_{2}-T_{1}\right) \\
c_{3} \dot{T}_{3}=+c_{3,1}\left(T_{3}-T_{1}\right)+c_{4,3}\left(T_{4}-T_{3}\right) \\
c_{4} \dot{T}_{4}=-c_{4,8}\left(T_{4}-T_{8}\right)-c_{4,3}\left(T_{4}-T_{3}\right) \\
c_{5} \dot{T}_{5}=c_{6,5}\left(T_{6}-T_{5}\right)-c_{5,1}\left(T_{5}-T_{1}\right) \\
c_{6} \dot{T}_{6}=c_{7,6}\left(T_{7}-T_{6}\right)-c_{6,5}\left(T_{6}-T_{5}\right) \\
c_{7} \dot{T}_{7}=c_{0,7}\left(T_{0}-T_{7}\right)-c_{7,6}\left(T_{7}-T_{6}\right)+q_{p} \\
c_{8} \dot{T}_{8}=c_{9,8}\left(T_{9}-T_{8}\right)+c_{4,8}\left(T_{8}-T_{4}\right) \text { when } Q>V \cdot \rho \cdot c_{p f} \text { else } T_{8}=-32^{\circ} \mathrm{C} \\
Q=\left(c_{4,8}\left(T_{4}-T_{8}\right)+c_{9,8}\left(T_{9}-T_{8}\right)\right) \cdot \tau \\
c_{9} \dot{T}_{9}=c_{10,9}\left(T_{10}-T_{9}\right)-c_{9,8}\left(T_{9}-T_{8}\right) \\
c_{10} \dot{T}_{10}=c_{11,10}\left(T_{11}-T_{10}\right)-c_{10,9}\left(T_{10}-T_{9}\right) \\
c_{11} T_{11}=c_{0,11}\left(T_{0}-T_{11}\right)-c_{11,10}\left(T_{11}-T_{10}\right) \\
c_{p t} T_{p t}=-c_{p t, 1}\left(T_{p t}-T_{1}\right)
\end{gathered}
$$

\section{Example of temperature simulation results in the body under analysis}

Values of coefficients $c_{i j}$ and $c_{i}$ :

$$
\begin{array}{lllll}
c_{1}=38400 \frac{\mathrm{J}}{\mathrm{K}} & c_{6}=497520 \frac{\mathrm{J}}{\mathrm{K}} & c_{0,1 \mathrm{~m}}=0.74 \frac{\mathrm{W}}{\mathrm{K}} & c_{3,1}=600 \frac{\mathrm{W}}{\mathrm{K}} & c_{10,9}=1.86 \frac{\mathrm{W}}{\mathrm{K}} \\
c_{2}=m \cdot c_{p} & c_{7}=226000 \frac{\mathrm{J}}{\mathrm{K}} & c_{0,1 \mathrm{~s}}=36.9 \frac{\mathrm{W}}{\mathrm{K}} & c_{3,4}=150 \frac{\mathrm{W}}{\mathrm{K}} & c_{11,10}=1.6 \frac{\mathrm{W}}{\mathrm{K}} \\
m=1000 \mathrm{~kg} & c_{8}=324000 \frac{\mathrm{J}}{\mathrm{K}} & c_{0,7}=4340 \frac{\mathrm{W}}{\mathrm{K}} & c_{4,8}=1000 \frac{\mathrm{W}}{\mathrm{K}} & c_{t h, 1}=0.036 \frac{\mathrm{W}}{\mathrm{K}} \\
c_{p}=4.19 \frac{\mathrm{kJ}}{\mathrm{kg} \cdot \mathrm{K}} & c_{9}=5577 \frac{\mathrm{J}}{\mathrm{K}} & c_{0,11}=133 \frac{\mathrm{W}}{\mathrm{K}} & c_{5,1}=1725 \frac{\mathrm{W}}{\mathrm{K}} & \\
c_{3}=4500 \frac{\mathrm{J}}{\mathrm{K}} & c_{10}=19793 \frac{\mathrm{J}}{\mathrm{K}} & c_{1,0}=0.78 \frac{\mathrm{W}}{\mathrm{K}} & c_{6,5}=42 \frac{\mathrm{W}}{\mathrm{K}} \\
c_{4}=4500 \frac{\mathrm{J}}{\mathrm{K}} & c_{11}=4113 \frac{\mathrm{J}}{\mathrm{K}} & c_{2,1}=\alpha \cdot \mathrm{F} & c_{7,6}=43.4 \frac{\mathrm{W}}{\mathrm{K}} & \\
c_{5}=187920 \frac{\mathrm{J}}{\mathrm{K}} & c_{p t}=3 \frac{\mathrm{J}}{\mathrm{K}} & \alpha=50 \frac{\mathrm{W}}{\mathrm{m}^{2} \cdot \mathrm{K}} & c_{9,8}=800 \frac{\mathrm{W}}{\mathrm{K}} &
\end{array}
$$

)

where $m$ - remaining mass of cargo (for $t=0, m=1000 \mathrm{~kg}$ ), $\mathrm{F}$ - remaining body of cargo (for $t=0, F=20 \mathrm{~m}^{2}$ ).

In the study it was assumed that air temperature during a hot summer day is approximately described by the relation:

$$
T_{0}=30+6 \sin 2 \pi\left(\frac{t+18}{24}\right)
$$

where: $T_{0}$ - ambient temperature, $t$ - hour of day.

The effect of solar radiation during a summer day was also taken into account. It was assumed that the irradiance supplies:

$$
q_{p}=\frac{A \cdot I}{2}+\frac{A \cdot I}{20}[J]
$$

where: $A$ - body surface area $\left(A=55 \mathrm{~m}^{2}\right), I$ - irradiance.

Sinusoidal irradiance value has been assumed and corresponds approximately to the effect of solar radiation in the urban zone on the walls of a vehicle of rectangular shape: 


$$
I=400+300 \sin 2 \pi\left(\frac{t-5}{24}\right)[W]
$$

For the purpose of the simulation, it was assumed that the vehicle departs from the base at $10.00 \mathrm{a} . \mathrm{m}$. and travels for the first 60 minutes to the point of unloading of a part of the cargo. Unloading takes 5 minutes. The vehicle then drives for a further 37 minutes to the next place of unloading. And so until the entire cargo is unloaded. At each standstill, 1/10 of the cargo leaves the vehicle.

Initial temperatures $\left({ }^{\circ} \mathrm{C}\right)$ :

$$
\begin{array}{llllll}
T_{0}=30 & T_{2}=-20 & T_{4}=-32 & T_{6}=20 & T_{8}=-32 & T_{10}=20 \\
T_{c z}, T_{1}=10 & T_{3}=10 & T_{5}=10 & T_{7}=30 & T_{9}=-32 & T_{11}=30
\end{array}
$$

The thermal capacity of proposed cooling reservoir is similar to thermal capacity of 4 eutectic plates Carrier VANTA 204 type and amount to $Q=12000 \mathrm{Wh}=43.2 \cdot 10^{6} \mathrm{~J}$. It was assumed that the body has $20 \mathrm{~m}^{3}$ capacity, insulation class R (reinforced, by $k=0.4 \frac{\mathrm{W}}{\mathrm{m}^{2} \mathrm{~K}}$ ) and wall area $A=55 \mathrm{~m}^{2}$.

The described system of equations (13 - 25) was modelled using the MATLAB Simulink package.

Sample results of body work simulation are presented in Fig. 3.

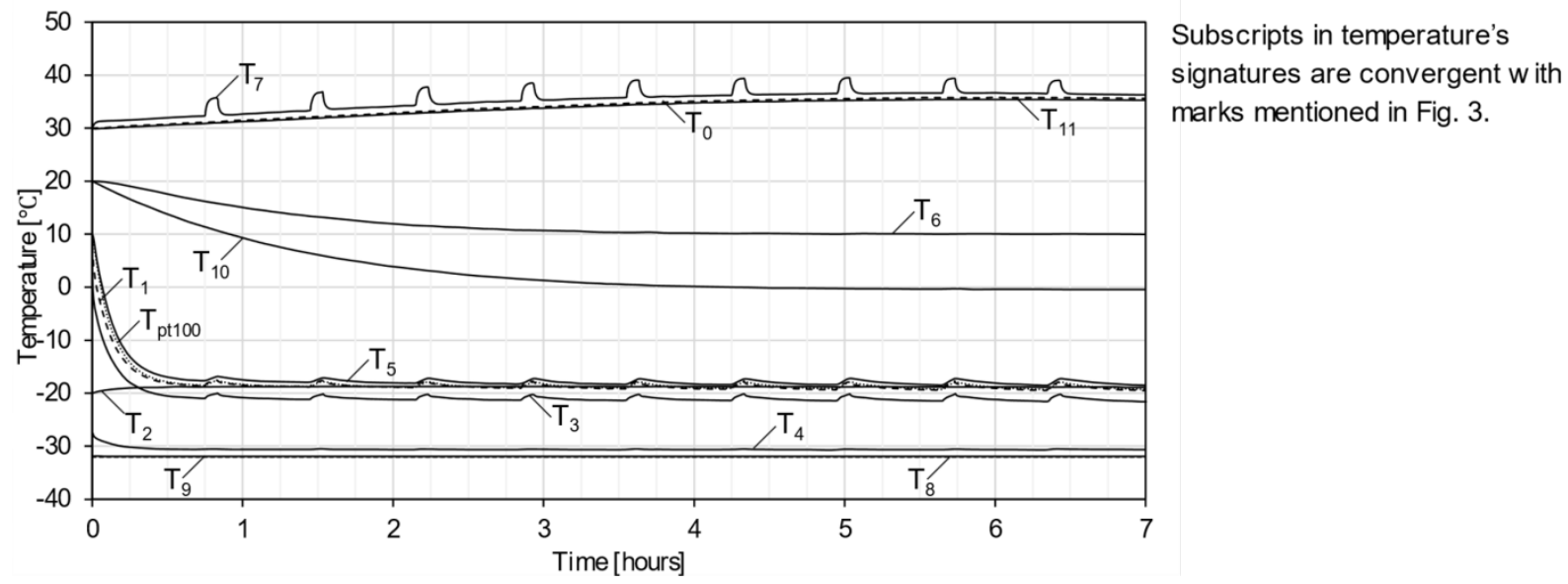

Fig. 3: Sample results of temperature changes in a refrigerated truck body circulating-cooled with the use of a cold reservoir.

\section{Summary}

The presented model allows for: comprehensive simulations of the influence of weather conditions, thermal insulation properties of the body, reservoir size for the duration of its operation. The model also makes it possible to optimise the size of the reservoir in view of operational needs. The described way of supplying the refrigerated body allows for rational use of energy accumulated in the cold reservoir. This is extremely important in this age of development of goods transport.

\section{References}

ATP, (1970) Agreement of the International Carriage of Perishable Foodstuffs and on the Special Equipment to be used for such Carriage (ATP), Geneva 1970.

Bienczak, K., Zwierzycki, W. (2006) Refrigeration vehicles in food transport, Poznan.

Kwasniowski, S. (1997) Isothermal and refrigeration vehicles, Wroclaw.

Kwasniowski, S., Grajnert J. (1998) Dynamics of heat exchange in the icehouse. Cooling magazine, 1998, 7, pp.2935.

SIMULINK, User’s Guide, Dynamic System Simulation Software. The Math Works Inc.

Zajac, P., Kwasniowski, S. (2015) Evaluation method of energy consumption in logistic warehouse systems, Springer, EcoProduction.

Zajac, P. (2017) Zero energy buildings in the logistics warehouse systems. In: International Conference on Advances in Energy Systems and Environmental Engineering ASEE17 (B. Kazmierczak eds.). EDP Sciences, art. 000198, pp.1-8. (E3S Web of Conferences, ISSN 2267-1242; vol. 22). 